\title{
Perception of Caudal Septal Dislocation and Practices of Otolaryngologists in Saudi Arabia
}

\author{
Ibrahim AlQuniabut ${ }^{1 *}$, Abdulaziz Abuabat ${ }^{2}$, Ibrahim AlAwadh ${ }^{3}$, Abdulrahman Alfarhan² ${ }^{2}$ and Abdullah Altuaysi ${ }^{4}$ \\ ${ }^{1}$ Department of Surgery, Unaizah College of Medicine and Medical Sciences, Qassim University, Kingdom of Saudi \\ ${ }^{2}$ College of Medicine, King Saud Bin Abdulaziz University for Health Sciences, Saudi Arabia
}

${ }^{3}$ Department of Surgery, King Abdulaziz University Hospital, Saudi Arabia

${ }^{4}$ Otolaryngology Head and Neck Surgery Department, King Saud Hospital, Saudi Arabia

Submission: April 04, 2021; Published: May 06, 2021

*Corresponding author: Ibrahim AlQuniabut, Assistant Professor of Otorhinolaryngology Head and Neck Surgery, Department of Surgery, Unaizah College of Medicine and Medical Sciences, Qassim University, Kingdom of Saudi Arabia

\section{Abstract}

Introduction: The nasal septum is the internal part of the nose, which holds a vital role in maintaining the functional and structural integrity. Considering its anterior location, the caudal septum is subjected to trauma, which makes it vulnerable to dislocation. This study aims to study the current practices and perception of otolaryngologists in Saudi Arabia in dealing with such cases.

Methodology: A survey study targeted otolaryngologists in Saudi Arabia.

Results: A total of 77 surgeons answered the survey. Septal repositioning was the most com-mon technique used by the participants. Asymmetrical nostrils and nasal obstruction were the two most common patient complaints. $67 \%$ of participants felt comfortable dealing with such cases and $32 \%$ were uncomfortable and refer cases to facial plastic specialists. Significant correlations were found between the area of specialization and the desired surgical outcome, with a p-value of 0.001 . Facial plastic specialists target functional and aesthetic outcomes, while non-facial plastic focus on functional outcomes. In addition, a significant difference was found in terms of comfort level and competency between non-facial plastic and facial-plastic otolaryngologists, with a p-value of 0.004 favoring the latter.

Conclusion: Discrepancies were found in terms of practices, perception, and comfort level in dealing with caudal septal dislocation among otolaryngologists in Saudi Arabia, suggesting that various surgical techniques are used in correcting caudal dislocation and that there is a diversity of cases presented in residency programs.

Keywords: Septal dislocation; Deviated nasal septum; Caudal dislocation; Septoplasty; Septum

\section{Introduction}

The nasal septum forms the foundation for the nasal pyramid, providing central support to the osseocartilaginous framework of the nose. The caudal septum is the inferior-anterior segment of the cartilaginous structure. The caudal septum extends beyond the anterior nasal spine and thus it can be subjected to trauma that can ultimately lead to deviation or dislocation [1]. The stability and functionality of the caudal septum is critical for maintaining the patency of the nasal nostrils. Caudally, the cartilaginous septum has a great impact on the shape of the dorsum of the nose and the nasal tip.

Nasal obstruction is a highly prevalent complaint in Saudi Arabia, and one that negatively affects patients' quality of life [2]. A deviation in the caudal septum can compromise the ex-ternal nasal valve, resulting in direct airway obstruction and impairment of the nasal airflow [1]. Cosmetically, caudal septal irregularities can drastically affect lobular and columellar relationships, dorsal shape and projection, and tip position and symmetry [3].

Caudal septal deviation constitutes $8 \%$ of patients with nasal septal deviation $[4,5]$. Many causes of caudal septal deviations have been addressed in the literature and can be classified as either traumatic or iatrogenic. Most commonly, this deformity is the result of the effects of trauma [6,7]. The challenges of correcting caudal septal deviations are undeniable $[8,9]$. This attributable to the unique property of the nasal intrinsic cartilage memory [5]. The literature shows significant differences of opinion regarding the appropriate technique used. [10,11] However, there is consensus regarding the main methods of addressing caudal nasal 


\section{Global Journal of Otolaryngology}

septum dislocation, [1] which be classified as cartilage reshaping or reconstruction. A wide variety of techniques for both methods have been introduced in the literature.

This study aims to report the practices and perceptions of otolaryngology surgeons in Saudi Arabia in dealing with caudal septal dislocation. To our knowledge, this is the first study to provide fundamental information concerning Saudi otolaryngologists' and facial plastic surgeons' approach to the caudal nasal septum. This study also focuses on awareness of surgical techniques and reviews the existing knowledge and current practice of otolaryngology specialists regarding the caudal nasal septum.

\section{Methodology}

\section{Study design}

This was a cross-sectional survey-based study targeting otolaryngology surgeons in Saudi Arabia. A self-developed questionnaire was distributed electronically, and participants

Results

Table 1: Demographic profile of the participants. were encouraged to take part. All otolaryngology consultants and board-certified physicians practicing in Saudi Arabia were included and targeted for the study. It contained several sections including demographic data, region of practice, and sections about types of surgical techniques used for caudal septal dislocation. A pilot study was conducted among 10 participants prior to the distribution to identify any issues or concerns with the interpretation of the questionnaire. Study was conducted upon approval in December 2020 up to January of 2021.

\section{Statistical analysis}

Data collection was done and entered in a pre-designed Microsoft Excel sheet. Extraction and analysis of the data was done using SPSS (Statistical Package for the Social Sciences) Version 22.

\section{Ethical considerations}

This study was approved by the Committee of Research Ethics, Deanship of Scientific Research, Qassim University (study number: 20-03-03) in December 2020 prior to conducting any steps in the study.

\begin{tabular}{|c|c|c|c|}
\hline \multicolumn{2}{|c|}{ Variables } & \multirow{2}{*}{$\begin{array}{c}\text { Number } \\
55\end{array}$} & \multirow{2}{*}{$\begin{array}{c}\text { Percentage } \\
71.40 \% \\
\end{array}$} \\
\hline Cond & Male & & \\
\hline Gentiet & Female & 22 & $28.50 \%$ \\
\hline \multirow{6}{*}{ Age } & $30-35$ & 34 & $44.20 \%$ \\
\hline & $36-40$ & 16 & $20.80 \%$ \\
\hline & $41-45$ & 9 & $11.70 \%$ \\
\hline & $46-50$ & 8 & $10.40 \%$ \\
\hline & $51-55$ & 5 & $6.50 \%$ \\
\hline & More than 55 & 5 & $6.50 \%$ \\
\hline \multirow{4}{*}{ Years of experience } & 5 Years or less & 11 & $14.30 \%$ \\
\hline & $6-10$ Years & 40 & $51.90 \%$ \\
\hline & 11 - 15 Years & 10 & $13.00 \%$ \\
\hline & More than 15 Years & 16 & $20.80 \%$ \\
\hline \multirow{5}{*}{ Region of practice } & Central region & 51 & $66.20 \%$ \\
\hline & Eastern region & 7 & $9.10 \%$ \\
\hline & Northern region & 1 & $1.30 \%$ \\
\hline & Western region & 8 & $10.40 \%$ \\
\hline & Southern region & 10 & $13.00 \%$ \\
\hline \multirow{3}{*}{ Type of practice } & Government hospital & 56 & $72.70 \%$ \\
\hline & Private hospital & 2 & $2.60 \%$ \\
\hline & Both & 19 & $24.70 \%$ \\
\hline \multirow{7}{*}{ Subspecialty } & General ENT & 36 & $46.80 \%$ \\
\hline & Head and neck & 10 & $13.00 \%$ \\
\hline & Facial plastic & 4 & $5.20 \%$ \\
\hline & Pediatric & 4 & $5.20 \%$ \\
\hline & Rhinology & 16 & $20.80 \%$ \\
\hline & Laryngology & 2 & $2.60 \%$ \\
\hline & Otology & 5 & $6.50 \%$ \\
\hline
\end{tabular}




\section{Global Journal of Otolaryngology}

Table 1 shows the profile of participants. A total of 77 participated in the study, $55(71 \%)$ of whom were males and 22 (28\%) were females. The age group 30 to 35 composed most of the participating physicians 34 (44\%), while physicians in the age groups 51 to 55 and 55 and above had the least number of

Table 2: Types of surgical techniques used. participants, with 5 (6.5\%) each. The majority (40;51\%) had from 6 to 10 years of experience. Most of the participants are based in the central region $(51 ; 66 \%)$. A total of $56(72 \%)$ participants reported working in a governmental hospital, 2 (2\%) in a private center, and 19 (24\%) reported working in both.

\begin{tabular}{|c|c|c|}
\hline Which of the following surgical techniques do you commonly use in your practice to correct caudal septal dislocation? \\
\hline Variables & $\mathbf{N}$ & 70.1 \\
\hline Septal reposition & 54 & $13.00 \%$ \\
\hline Spreader graft & 10 & $29.90 \%$ \\
\hline Wedging, scoring, or morselization & 23 & $62.30 \%$ \\
\hline Suturing technique & 48 & $3.90 \%$ \\
\hline Batten grafting & 3 & $37.70 \%$ \\
\hline Tongue in groove & 29 & $0.00 \%$ \\
\hline Extracorporeal excision & 0 & $0.00 \%$ \\
\hline PDS Foil & 0 & $0.00 \%$ \\
\hline Costal cartilage & 0 & $0.00 \%$ \\
\hline Non-autologous material & 0 & \multicolumn{2}{|c|}{} \\
\hline
\end{tabular}

Table 2 reports participants' answers to what the common techniques are that are used in their own practice. A total of $54(70 \%)$ participants said that they commonly use the septal repositioning technique. The second most common technique was the suturing technique (48; 62\%), followed by the tonguein-groove $(29 ; 37 \%)$, and the wedging, scoring, or morselization technique $(23 ; 29 \%)$. Regarding the number of caudal septal dislocation patients seen by our participants in their practice per month, the majority $(63 ; 81 \%)$ reported seeing less than 5 cases, $10(13 \%)$ saw between 5 to 10 cases per month, three (3\%) reported seeing between 11 to 15 cases, and 1 (1\%) reported seeing more than 15 cases per month.

Table 3 shows the association between years of experience as an otolaryngological surgeon and the level of comfort in dealing with caudal septal dislocation cases, utilizing a chi-square test with a p-value of .001. Surgeons who had 5 years or less experience $(5 ; 45 \%)$ felt uncomfortable. Most surgeons $(12 ; 30 \%)$ who had between 6 to 10 years' experience felt semi-comfortable. A large number $(16 ; 61 \%)$ of surgeons with more than 11 years' experience were semi-comfortable.

Table 3: Relationship between years of experience as an otolaryngologist and level of comfort in dealing with septal dislocation patients.

\begin{tabular}{|c|c|c|c|c|c|c|c|c|}
\hline & & & \multicolumn{5}{|c|}{ Comfort Level } & \multirow[b]{2}{*}{ Total } \\
\hline & & & $\begin{array}{c}\text { Refer to Facial } \\
\text { Plastic Sur- } \\
\text { geon }\end{array}$ & Uncomfortable & $\begin{array}{l}\text { Semi-com- } \\
\text { fortable }\end{array}$ & Comfortable & Very Comfortable & \\
\hline \multirow{6}{*}{$\begin{array}{l}\text { Years of expe- } \\
\text { rience as an } \\
\text { ENT surgeon }\end{array}$} & \multirow{2}{*}{$\begin{array}{l}5 \text { years or } \\
\text { less }\end{array}$} & Count & 3 & 5 & 3 & 0 & 0 & 11 \\
\hline & & $\%$ & $27.30 \%$ & $45.50 \%$ & $27.30 \%$ & $0.00 \%$ & $0.00 \%$ & $100.00 \%$ \\
\hline & \multirow{2}{*}{$\begin{array}{l}6-10 \\
\text { years }\end{array}$} & Count & 4 & 10 & 12 & 10 & 4 & 40 \\
\hline & & $\%$ & $10.00 \%$ & $25.00 \%$ & $30.00 \%$ & $25.00 \%$ & $10.00 \%$ & $100.00 \%$ \\
\hline & \multirow{2}{*}{$\begin{array}{l}11-15 \\
\text { years }\end{array}$} & Count & 0 & 0 & 16 & 5 & 5 & 26 \\
\hline & & $\%$ & $0.00 \%$ & $0.00 \%$ & $61.50 \%$ & $19.20 \%$ & $19.20 \%$ & $100.00 \%$ \\
\hline
\end{tabular}

P-Value: 001

Table 4 shows the comfort level in association with the area of specialization ( $\mathrm{p}=0.004)$. Most non-facial plastic otolaryngologists said they felt semi-comfortable in dealing with those cases, whereas most facial plastic specializing otolaryngologists felt very comfortable with them. Table 5 shows the association between the area of specialization and the desired surgical outcomes post-surgery for caudal septal dislocation. Practicing as a general otolaryngologist $(32 ; 88 \%)$ was associated with considering 


\section{Global Journal of Otolaryngology}

both functional and aesthetic outcomes in dealing with those patients with a $(\mathrm{p}=0.001)$ and working as a subspecialized non-facial plastic otolaryngologist $(18 ; 48 \%)$ was associated with considering functional outcomes to a greater extent ( $\mathrm{p}$ -
$=0.001$ ). Regarding subspecialty, working as a specialized facial plastic surgeon $(4 ; 100 \%)$ was associated with considering both outcomes $(p=0.001)$.

Table 4: Level of Comfort in Dealing with Caudal Septal Dislocation Patients.

\begin{tabular}{|c|c|c|c|c|c|c|}
\hline & $\begin{array}{c}\text { Refer to Facial Plastic } \\
\text { Surgeon }\end{array}$ & Uncomfortable & $\begin{array}{c}\text { Semi-Comfort- } \\
\text { able }\end{array}$ & Comfortable & $\begin{array}{c}\text { Very Comfort- } \\
\text { able }\end{array}$ & Total \\
\hline $\begin{array}{c}\text { General otolaryngol- } \\
\text { ogists }\end{array}$ & 4 & 6 & 17 & 4 & 5 \\
\hline Other specialties & 3 & 9 & 14 & 10 & 1 & 36 \\
\hline Facial plastic & 0 & 0 & 0 & 1 & 3 & 4 \\
\hline Total & 7 & 15 & 31 & 15 & 9 \\
\hline
\end{tabular}

P-Value: .001

Table 5: Primary outcome goals in caudal septal dislocation cases.

\begin{tabular}{|c|c|c|c|c|c|}
\hline \multicolumn{2}{|c|}{} & Functional Outcomes & Aesthetic Outcomes & Both & 32 \\
\hline \multirow{2}{*}{ General otolaryngologists } & Count & 3 & 1 & $88.90 \%$ & $100.00 \%$ \\
\cline { 2 - 6 } & $\%$ & $8.30 \%$ & $2.80 \%$ & 17 & 37 \\
\hline \multirow{2}{*}{ Other specialties } & Count & 18 & $5.40 \%$ & $45.90 \%$ & 4 \\
\cline { 2 - 6 } & $\%$ & $48.60 \%$ & 0 & $100.00 \%$ \\
\hline \multirow{2}{*}{ Facial plastic } & Count & 0 & $0.00 \%$ & $100.00 \%$ & $100.00 \%$ \\
\cline { 2 - 6 } & $\%$ & $0.00 \%$ & 2 & 4 & 36 \\
\hline
\end{tabular}

P-Value: .001

\section{Discussion}

To our knowledge, this is the first study in the literature to discuss and report the current practices and perceptions of otolaryngologists in Saudi Arabia in dealing with caudal septal dislocation. Caudal septal dislocation is challenging to repair, with many proposed techniques aiming to achieve the most desirable aesthetic and functional outcomes [8]. Failure to address caudal septal dislocation appropriately can result in many devastating functional and cosmetic consequences, resulting in possible need for revisional surgery. Septal repositioning and suturing techniques were the two most popular surgical techniques among our participants. These results contrast with the findings of a study that evaluated the practices of otolaryngologists in North America, where the two most popular techniques for caudal correction were swinging door and extracorporeal septoplasty, $69 \%$ and $46 \%$, respectively [12].

Table 3 shows the relationship between years of experience as an otolaryngologist and comfort level in dealing with caudal septal dislocation. In our study, surgeons with 11 or more years' experience prefer to be more conservative with caudal septal dislocation, as they tend to be semi-comfortable in dealing with such cases and unlikely to refer them to a facial-plastic specialist. Interestingly, we found in our study that surgeons with 6-10 years' experience showed extreme and contradicting preferences of either being uncomfortable with them and tending to refer them to specialized facial plastic or comfortable in dealing with caudal dislocation cases. However, for future research it is worth investigating whether this lack of comfort in dealing with caudal septal dislocation among junior surgeons is due to a lack of training and exposure to such cases during residency training or a sub specialization effect. Data from such studies can be useful in determining weaknesses in residency training and correcting them for future generations of surgeons.

In Table 4, we can see a significant difference in comfort level about area of specialization. Otolaryngologists specializing in facial-plastic were overall more confident and comfortable dealing with caudal septal dislocation patients, while the selfreported comfort level of otolaryngologists not specializing in facial-plastics varied, with the majority feeling semi-comfortable. This raises the important question of whether these differences reflect an actual lack of exposure and training in dealing with caudal septal dislocation patients, and whether more emphasis is needed to be put in place during residency training to train future otolaryngologists to feel more confident and experienced with such patients.

As shown in Table 5, we again see a difference between facialplastic otolaryngologists and non-facial plastic otolaryngologists in terms of desired post-correction outcome in caudal septal 
dislocation. All the facial-plastic otolaryngologists surveyed target functional and aesthetic improvement with equal importance. However, answers from surgeons from different areas of practice (i.e., general otolaryngologists and other specialties of otolaryngology) varied from targeting solely functional outcomes or favoring both functional and aesthetic outcomes. All in all, these findings show that although post-correction aesthetic goals are important, most surgeons prioritize achieving functional improvement of their patients above all else.

\section{Conclusion}

Our study discussed the current practices and perceptions of otolaryngologists in dealing with caudal septal dislocation in Saudi Arabia, an ambiguous area of practice in otolaryngology with many proposed techniques, the most popular of which among our participants was the septal repositioning and suturing technique. Significant associations were found among self-reported comfort level, area of specialization, and years of experience as an otolaryngologist. These findings can promote further research in this area to investigate whether residency pro-grams in the Kingdom of Saudi Arabia have sufficient training and exposure for their trainees in dealing with caudal septal dislocation cases.

\section{Acknowledgement}

We would like to acknowledge and thank all the physicians across the country who participated in this study.

\section{References}

1. Haack J, Papel ID (2009) Caudal septal deviation. Otolaryngol Clin North Am 42(3): 427-436.
2. Daghistani K (2002) Nasal septal deviation in Saudi patients: A hospital-based study. J King Abdulaziz Univ Sci 10(1): 39-46.

3. Guyuron B, Behmand RA (2003) Caudal nasal deviation. Plast Reconstr Surg 111(7): 2449-2457.

4. Guyuron B, Uzzo CD SH (1999) A practical classification of septonasal deviation and an effective guide to septal surgery. Plast Reconstr Surg 104(7): 2202-2212.

5. Seo HS, Na HS, Kim SD, Yi KI, Mun SJ, Cho KS (2020) Septal cartilage traction suture technique for correction of caudal septal deviation. Laryngoscope 1-6.

6. Younes A, El Dsowkey R, Sameh M R, Hosam E R, Mohamed N E (2019) An algorithm for management of nasal caudal septal deformities. Egypt J Otolaryngol 35(4): 352-356.

7. Colton J, Beekhuis G (1986) Management of nasal fractures. Otolaryngol Clin North Am 19(1): 73-85.

8. Sedwick JD, Lopez AB, Gajewski BJ, Simons RL (2005) Caudal septoplasty for treatment of septal deviation: Aesthetic and functional correction of the nasal base. Arch Facial Plast Surg 7(3): 158-162.

9. Jin HR, Kim DW, Jung HJ (2018) Common sites, etiology, and solutions of persistent septal deviation in revision septoplasty. Clin Exp Otorhinolaryngol 11(4): 288-292.

10. Han JK, Stringer SP, Rosenfeld RM, Archer SM, Baker DP, et al. (2015) Clinical consensus statement: septoplasty with or without inferior turbinate reduction. Otolaryngol Head Neck Surg 153(5): 708-720.

11. Lee JW, Baker SR (2013) Correction of caudal septal deviation and deformity using nasal septal bone grafts. JAMA Facial Plast Surg 15(2): 96-100.

12. Voizard B, Theriault M, Lazizi S, Moubayed SP (2020) North American survey, and systematic review on caudal Septoplasty. J OtolaryngolHead \& Neck Surg 49: 1-0.

\section{Your next submission with Juniper Publishers will reach you the below assets}

- Quality Editorial service

- Swift Peer Review

- Reprints availability

- E-prints Service

- Manuscript Podcast for convenient understanding

- Global attainment for your research

- Manuscript accessibility in different formats

( Pdf, E-pub, Full Text, Audio)

- Unceasing customer service

Track the below URL for one-step submission https://juniperpublishers.com/online-submission.php 